\title{
Parameter analysis of stability bearing capacity of bottom frame beam for container building
}

\author{
Songfeng Sun ${ }^{1}$, Penggang Guo ${ }^{2 *}$, Qingyu Zhang ${ }^{1}$, Baoguang Chen ${ }^{1}$, Pingping Zhang ${ }^{1}$ \\ ${ }^{1}$ China State Construction Development Co., Ltd. Beijing 100037, China \\ ${ }^{2}$ China State Construction Engineering Corporation Limited Technical Center, Beijing 101300, China
}

\begin{abstract}
In this paper, the bottom frame beam of container building is analyzed by finite element method, and compared with the experimental results, the accuracy of the model is verified to meet the needs of the analysis. On this basis, by changing the stiffening position of the upper flange, the height of the web, the load layout and the thickness of the wall, the variation of the stability bearing capacity of the bottom frame beam was studied, the control factors affecting the stability bearing capacity of the bottom frame beam were obtained, and the selection suggestions were given.
\end{abstract}

\section{Introduction}

The container building consists of steel frame and maintenance structure. The wall board is sandwich board, which is fixed by the reserved slot and connecting parts between the column and beam. This kind of building is suitable for earthquake relief, construction site, commercial exhibition hall and other projects. After technical specification for modular freight container building ${ }^{[1]}$ has been issued in 2013, more and more

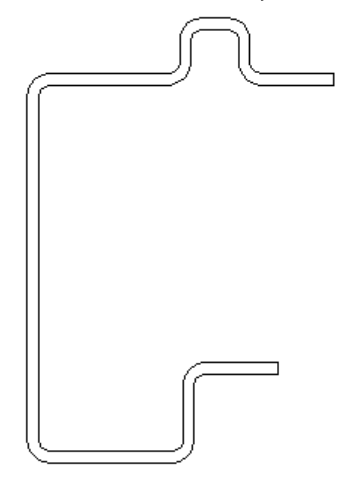

Figure 1. Bottom beam section.

Bottom frame beam is required higher stress deformation as chamber room floor beam. On the basis of experimental study, by changing the top flange stiffener location, web height, loading method, wall thickness, the stability bearing capacity of bottom frame beam is studied in this paper. It is concluded that the influence factors on the bearing capacity of bottom frame beam, and the selection suggestions were given.

\footnotetext{
${ }^{*}$ Corresponding author's e-mail: guopenggang@escec.com
}

scholars have carried out research on container building ${ }^{[2-5]}$. Technical standard for modular facilities in construction site ${ }^{[6]}$ came into being.

Bottom frame beam is the main bending member in the structural system of container building. C-section transformation is adopted to ensure that the connection between the beam and the wallboard and floor meets the structural requirements. Its section form is shown in figure 1 , and its connection structure is shown in figure 2.

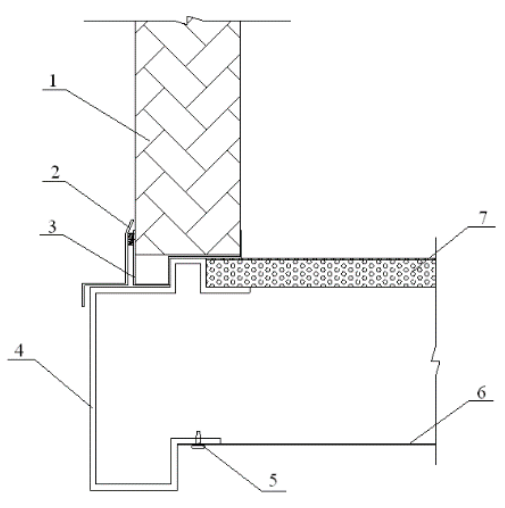

Figure 2. Bottom frame connection diagram. 1.wall; 2. mound bar; 3. warp; 4. beam; 5 . rivet; 6 . steel board; 7 . cement particle board.

\section{Material and Methods}

\subsection{Experimental study}

The test device of the beam is shown in figure 3 . The beam end is hinge joint and the load acts on the upper flange. Hydraulic jacks are used for graded loading and data acquisition instrument is used for real-time data 
acquisition. The final failure of the specimen is shown in

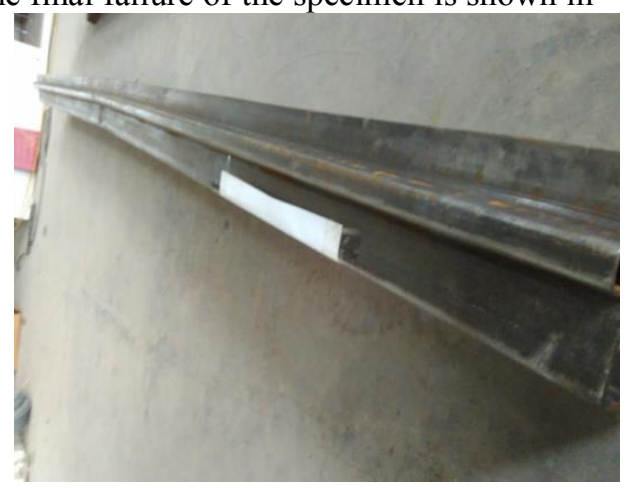

Figure 3. Concentrated load at mid-span.

Under the action of mid-span concentrated load and three-point concentrated load, the final failure mode of bottom frame beam is relatively similar, both of which end in the failure of overall bending and torsion, and there is no local buckling or distorted buckling in the test process.

\subsection{Numerical simulation}

ANSYS was used for numerical simulation. Ideal elastic-plastic stress-strain relationship, elastic modulus $E=2.11 \times 10^{5} \mathrm{Mpa}$, yield strength $f_{y}=337.35 \mathrm{Mpa}$, poisson's ratio $v=0.3$ were used. In this paper, the stable bearing capacity of the bottom frame beam is the key point. The figure 4.

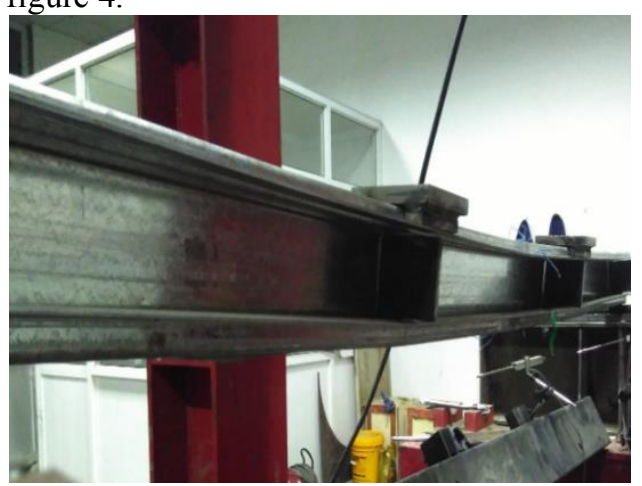

Figure4. Concentrated load at three points.

ideal elastic-plastic model is adopted for the stress-strain relationship of steel in nonlinear analysis.

According to the technical specification for cold-formed thin-walled steel structures (GB50018) ${ }^{[7]}$, the initial geometric defect of the specimen is assumed to be sine half wave, and the peak value is $1 / 750$ of the length of the member. In the variable parameter simulation, theoretical values are used for convenience.

\subsection{Comparison of results}

Table 1 shows the comparison of the maximum bearing capacity obtained by the test and numerical simulation of the bottom frame beam, where $p^{t}$ is the mean value of the experiments, $p^{a}$ is the simulated value of ANSYS.

Table 1 . Comparison of the maximum bearing capacity.

\begin{tabular}{lcccc}
\hline Specimen number & $\begin{array}{c}\text { Plate thickness } \\
/ \mathrm{mm}\end{array}$ & \multicolumn{3}{c}{ Comparison of the maximum bearing capacity } \\
& 4 & 27.03 & 31.02 & $P^{t} / P^{t}$ \\
\hline BPBS4-2688-1 & 4.5 & 22.13 & 26.0 & 1.14 \\
BPBS3.5-2688-1 & 3 & 17.85 & 19.84 & 1.17 \\
BPBS3-2688-1 & 4 & 47.32 & 50.16 & 1.11 \\
BPBS4-2688-2 & 3.5 & 36.90 & 42.06 & 1.14 \\
BPBS3.5-2688-2 & 3 & 31.95 & 33.01 & 1.03 \\
\hline
\end{tabular}

The analysis shows that the ANSYS simulation results of most specimens are slightly higher than the test results, with a maximum error of $17 \%$ and the rest within $15 \%$. It can be considered that the ANSYS simulation is reasonable.

\section{Results and Discussion}

The specimens were all $2688 \mathrm{~mm}$ in length. The influence of stiffening position of upper flange, depth-thickness ratio of web, loading mode and wall thickness on bending performance of bottom frame beam was analysed.

\subsection{Stiffening position on compression flange}

Change the compression flange stiffener location variable parameter analysis, finite element numbering rules as shown in figure $5, \mathrm{BPB}$ on behalf of the bottom frame beam, flange stiffener location can be divided into three, L represents the location far from the web reinforcement, $M$ represents the middle web reinforcement, $\mathrm{R}$ represents the location near web reinforcement, corresponding figure 6 (b) (c) (d), thickness consist of $4 \mathrm{~mm}, 3.5 \mathrm{~mm}, 3 \mathrm{~mm}$, load consist of mid-span concentrated load and three point load concentrated load.

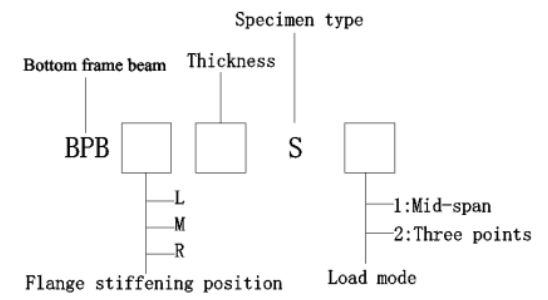

Figure 5. the numbering rules of specimen. 


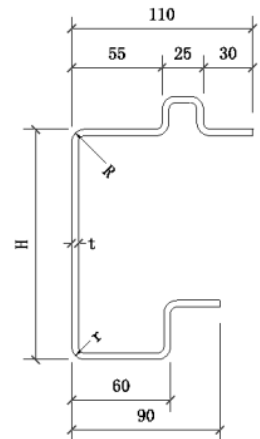

(a) Original.

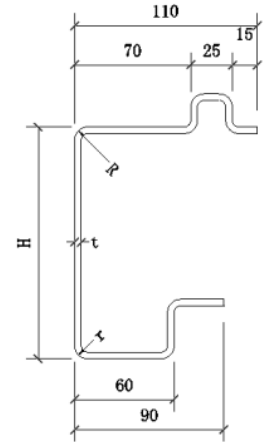

(b) Far stiffening.

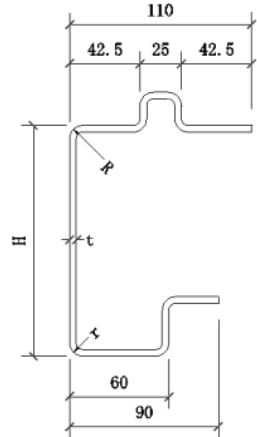

(c) Middle stiffening.

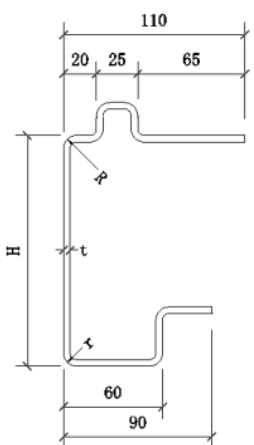

(d) Near stiffening.

Figure 6. Section form and geometric parameters.

The stability bearing capacity of each specimen is shown in table 2 , In which, $p^{A}$ represents the result of

variable parameter analysis and calculation, $p^{A O}$ represents the original cross section calculation result.

Table2. The results of bottom frame beam changing the stiffening position of compression flange.

\begin{tabular}{clccc|ccccc}
\hline & $\begin{array}{l}\text { Specimen } \\
\text { number }\end{array}$ & $\begin{array}{c}p^{A} \\
/ K N\end{array}$ & $\begin{array}{c}p^{A O} \\
/ K N\end{array}$ & $\begin{array}{c}\left(p^{A}-p^{A o}\right) \\
/ p^{A o}\end{array}$ & $\begin{array}{l}\text { Specimen } \\
\text { number }\end{array}$ & $\begin{array}{c}p^{A} \\
/ K N\end{array}$ & $\begin{array}{c}p^{A O} \\
/ K N\end{array}$ & $\begin{array}{c}\left(p^{A}-p^{A o}\right) \\
/ p^{A o}\end{array}$ \\
\hline 1 & BPBL4S1 & 31.96 & 31.02 & $3.03 \%$ & 10 & BPBL4S2 & 53.74 & 50.15 & $7.16 \%$ \\
2 & BPBM4S1 & 31.11 & 31.02 & $0.29 \%$ & 11 & BPBM4S2 & 50.82 & 50.15 & $1.34 \%$ \\
3 & BPBR4S1 & 34.70 & 31.02 & $11.86 \%$ & 12 & BPBR4S2 & 56.32 & 50.15 & $12.30 \%$ \\
4 & BPBL3.5S1 & 27.02 & 26.36 & $2.50 \%$ & 13 & BPBL3.5S2 & 44.23 & 43.29 & $2.17 \%$ \\
5 & BPBM3.5S1 & 25.75 & 26.36 & $-2.31 \%$ & 14 & BPBM3.5S2 & 41.32 & 43.29 & $-4.55 \%$ \\
6 & BPBR3.5S1 & 28.90 & 26.36 & $9.64 \%$ & 15 & BPBR3.5S2 & 47.11 & 43.29 & $8.80 \%$ \\
7 & BPBL3S1 & 20.80 & 19.84 & $4.84 \%$ & 16 & BPBL3S2 & 35.11 & 32.07 & $9.48 \%$ \\
8 & BPBM3S1 & 19.75 & 19.84 & $-0.45 \%$ & 17 & BPBM3S2 & 32.27 & 32.07 & $0.62 \%$ \\
9 & BPBR3S1 & 22.83 & 19.84 & $15.07 \%$ & 18 & BPBR3S2 & 37.94 & 32.07 & $18.30 \%$ \\
\hline
\end{tabular}

In which, $p^{A}$ represents the result of variable parameter analysis and calculation, $p^{A O}$ represents the original cross section calculation result.

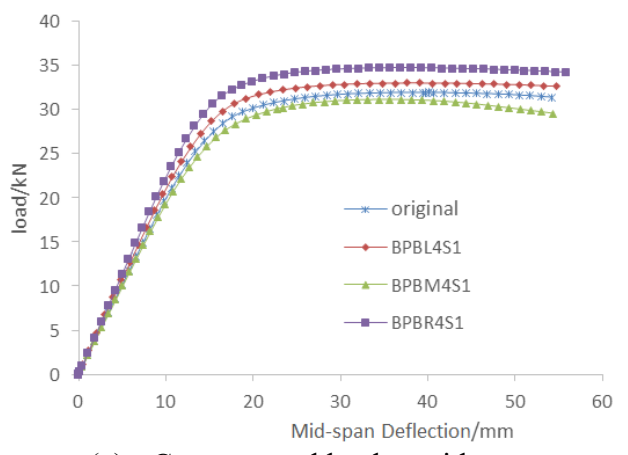

(a) Concentrated load at mid-span.
The load-displacement curve statistics of $4 \mathrm{~mm}$ specimen is shown in figure 7. Due to limited space, other thickness specimens are not listed here.

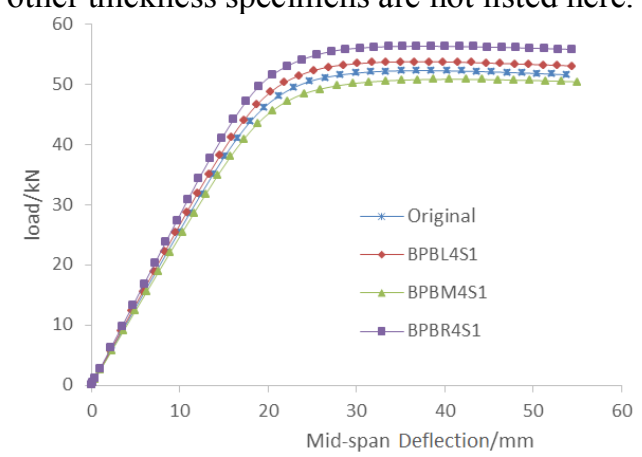

(b) Concentrated load at three points.

Figure 7. The load-displacement curve statistics of $4 \mathrm{~mm}$ specimen.

AS showed in table 2 and figure 7.

Under concentrated mid-span load, when the stiffening position of the compression flange is in the middle position, its bearing capacity is close to that of the original section; when the stiffening position of the compression flange is away from the web, the bearing capacity increases by more than $2.50 \%$; when the compression flange stiffening position is close to the web, the bearing capacity increases by more than $9.64 \%$.

Under the concentrated load of three points, when the stiffening position of the compression flange is in the middle position, its bearing capacity is relatively close to that of the original section; when the stiffening position of the compression flange is away from the web, the bearing capacity increases by more than $2.17 \%$; when the compression flange stiffening position is close to the web, the bearing capacity increases by more than $8.80 \%$.

\subsection{Depth-thickness ratio of web}

The finite element specimens were numbered in the analysis, and the numbering rules are shown in figure 4.6. BPB represents the bottom frame beam, the height of the web is $100 \mathrm{~mm}, 120 \mathrm{~mm}, 160 \mathrm{~mm}$ and $180 \mathrm{~mm}$, and the thickness of the plate is $4 \mathrm{~mm}, 3.5 \mathrm{~mm}$ and $3 \mathrm{~mm}$, load consist of mid-span concentrated load and three point load concentrated load. 


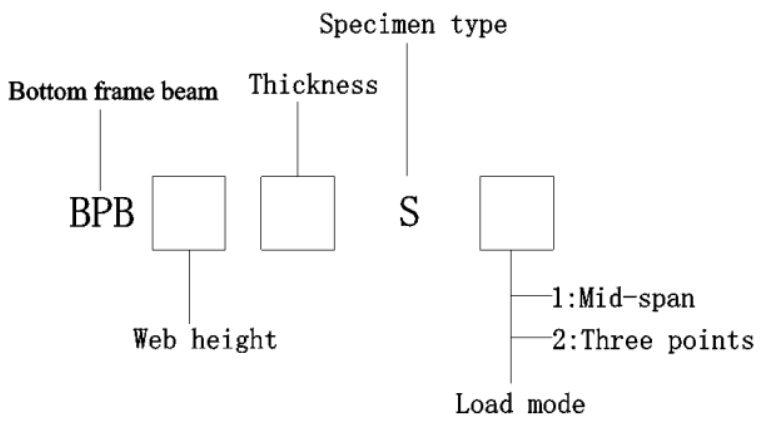

Figure 8. the numbering rules of specimen.

The stability bearing capacity of each specimen is shown in table 3 .

Table 3. Influence of different web depth-thickness ratio on stability bearing capacity.

\begin{tabular}{clccc|clccc}
\hline & $\begin{array}{l}\text { Specimen } \\
\text { number }\end{array}$ & $\begin{array}{c}p^{4} \\
/ K N\end{array}$ & $\begin{array}{c}p^{A O} \\
/ K N\end{array}$ & $\begin{array}{c}\left(p^{A}-p^{A o}\right) \\
/ p^{A o}\end{array}$ & $\begin{array}{l}\text { Specimen } \\
\text { number }\end{array}$ & $\begin{array}{c}p^{4} \\
/ K N\end{array}$ & $\begin{array}{c}p^{4 O} \\
/ K N\end{array}$ & $\begin{array}{c}\left(p^{A}-p^{A o}\right) \\
/ p^{A o}\end{array}$ \\
\hline 1 & BPB100-4S1 & 24.17 & 31.02 & $-22.08 \%$ & 13 & BPB100-4S2 & 36.70 & 50.15 & $-26.82 \%$ \\
2 & BPB120-4S1 & 28.36 & 31.02 & $-8.58 \%$ & 14 & BPB120-4S2 & 45.07 & 50.15 & $-10.13 \%$ \\
3 & BPB160-4S1 & 34.81 & 31.02 & $12.22 \%$ & 15 & BPB160-4S2 & 57.89 & 50.15 & $15.43 \%$ \\
4 & BPB180-4S1 & 37.00 & 31.02 & $19.28 \%$ & 16 & BPB180-4S2 & 62.35 & 50.15 & $24.33 \%$ \\
5 & BPB100-3.5S1 & 20.56. & 26.36 & $-22.00 \%$ & 17 & BPB100-3.5S2 & 31.69 & 43.29 & $-26.80 \%$ \\
6 & BPB120-3.5S1 & 23.77 & 26.36 & $-9.83 \%$ & 18 & BPB120-3.5S2 & 38.00 & 43.29 & $-12.22 \%$ \\
7 & BPB160-3.5S1 & 29.04 & 26.36 & $10.17 \%$ & 19 & BPB160-3.5S2 & 47.63 & 43.29 & $10.03 \%$ \\
8 & BPB180-3.5S1 & 30.70 & 26.36 & $16.46 \%$ & 20 & BPB180-3.5S2 & 51.02 & 43.29 & $17.86 \%$ \\
9 & BPB100-3S1 & 16.51 & 19.84 & $-16.78 \%$ & 21 & BPB100-3S2 & 26.49 & 32.07 & $-17.40 \%$ \\
10 & BPB120-3S1 & 18.36 & 19.84 & $-7.46 \%$ & 22 & BPB120-3S2 & 31.42 & 32.07 & $-2.03 \%$ \\
11 & BPB160-3S1 & 22.05 & 19.84 & $11.14 \%$ & 23 & BPB160-3S2 & 37.50 & 32.07 & $16.93 \%$ \\
12 & BPB180-3S1 & 23.04 & 19.84 & $16.13 \%$ & 24 & BPB180-3S2 & 39.63 & 32.07 & $23.57 \%$ \\
\hline
\end{tabular}

The load-displacement curve statistics of $4 \mathrm{~mm}$ specimen is shown in figure 9. Due to limited space, other thickness specimens are not listed here.

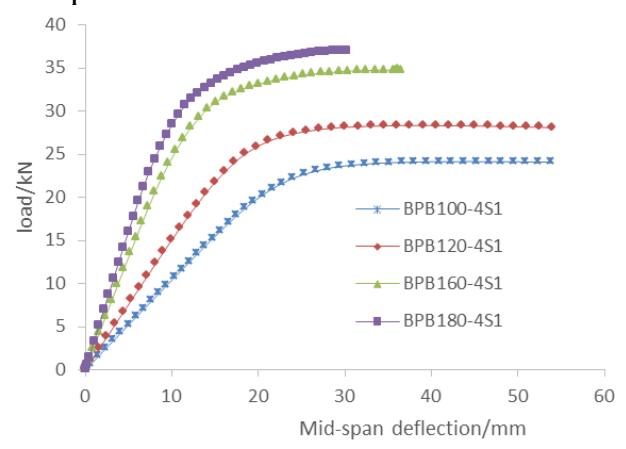

(a) Concentrated load at mid-span.

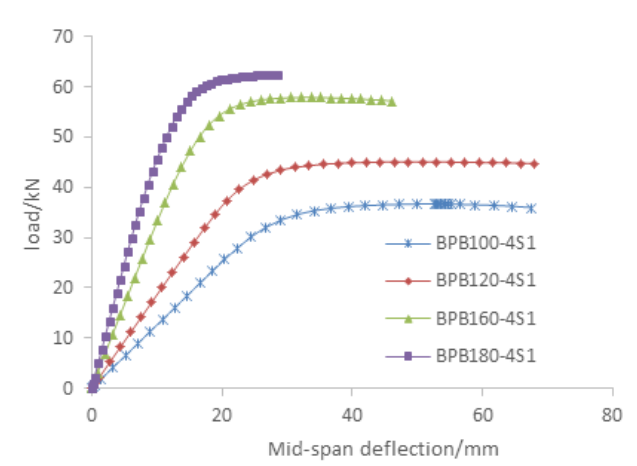

(b) Concentrated load at three points.

Figure 9. The load-displacement curve statistics of $4 \mathrm{~mm}$ specimen.

AS showed in table 3 and figure 9.

Under mid-span concentrated load, when the height of the web is $100 \mathrm{~mm}$, the stability bearing capacity of the specimen decreases by at least $16.78 \%$; when the web height is $120 \mathrm{~mm}$, the stability bearing capacity of the specimen decreases by at least $7.46 \%$; when the web height is $160 \mathrm{~mm}$, the stability bearing capacity of specimens increases by at least $10.17 \%$; when the web height is $180 \mathrm{~mm}$, the stability bearing capacity of specimens is increased by at least $16.13 \%$.

Under the concentrated load of three points, when the height of the web was $100 \mathrm{~mm}$, the stability bearing capacity of the specimen decreased by at least $17.40 \%$; when the web height is $120 \mathrm{~mm}$, the stability bearing capacity of the specimen decreases by at least $2.03 \%$; when the web height is $160 \mathrm{~mm}$, the stability bearing capacity of specimens increases by at least $10.03 \%$; when the web height is $180 \mathrm{~mm}$, the stability bearing capacity of specimens increases by at least $17.86 \%$.

\section{Conclusions}

In this paper, the bottom frame beam is simulated and calculated to verify the correctness of the numerical model. By changing the stiffening position, web height, thickness and loading mode for variable parameter analysis, the following conclusions can be drawn: 
The bearing capacity of the stiffener near the web is higher than the original section. The bearing capacity of the stiffener in the middle or away from the web is less than the original section. That is to say, under the condition of satisfying the requirements of the structure, the stiffener of the bottom frame beam compression flange is close to the web, which is a good section form, and when the stability bearing capacity of the specimen is higher, it is more scientific and reasonable to change the thickness of the specimen.

The change of web height will cause the change of beam stability bearing capacity. With the increase of web height, the bearing capacity of beam stability increases. The increment of section material caused by increasing web height is less than that caused by increasing wall thickness, namely when the stable bearing capacity of the specimens for higher, under the condition of construction and economy, can give priority to increase web height, and when the stable bearing capacity of the specimens have higher requirements, change the specimen thickness is more scientific and reasonable.

\section{Acknowledgement}

Supported by National key scientific research project (Grant No. 2016YFC0702102) "the study and demonstration of temporary facilities of construction site standardization 、canalization 、industrialization"

\section{References}

1. CECS. (2013) Technical specification for modular freight container building. China planning press, Beijing.

2. Yang DY. (2017) Study on the mechanical behavior of disassembled box housing structure. Zhengzhou University, Zhengzhou.

3. Wang W. (2017) Research on mechanical properties and design methods of multi-story box modular building. Xi'an University of Architecture and Technology, Xi'an.

4. Chen SY. (2009) Research on the optimization design of the components and the whole of the box integrated room. Harbin Institute of Technology, Haerbin.

5. Zhang JF, Yang DY, Hu WT. (2016) Study on the overall bending rigidity of disassembled box housing. Steel Structure, 31(12): 28-32.

6. GB. (2018) Technical standard for modular facilities in construction site. China building industry press, Beijing.

7. GB. (2002) Technical specification for cold-formed thin-walled steel structures. China planning publishing house, Beijing. 